\title{
Letter to the Editor: Exponential Increase in COVID-19 Related Publications Compared to Other Pandemic Diseases
}

\author{
Antonio Liu, M.D.* \\ Neurology, Adventist Health White Memorial, Los Angeles, CA, USA
}

\section{TO THE EDITOR}

I read the article by Dr Pitlik on COVID-19 with great interest. ${ }^{1}$ The number of publications related to the current pandemic as well as how readily available they are is yet another difference between COVID-19 and previous pandemic diseases.

When I wrote my first case report on a COVID-19 patient with meningoencephalitis in early April 2020, a literature search back then on PubMed.gov under the keyword "COVID-19" yielded a total of roughly 3,000 articles already. There has been an exponential increase in the amount of literature since. The same search today (August 22, 2020) yielded 42,693 entries. Of these, only 17 came from 2019; 42,679 are in print since January 1, 2020. Table 1 (following page) is a tabulation of the literature count for COVID-19 and selected previous pandemic diseases as outlined by Dr Pitlik.
There is obvious similarity between "COVID-19," "MERS," and "SARS." At roughly 200 new articles per day, it is a rather overwhelming amount for any scholar, physician, or administrator to digest. The number of articles per day will continue to go upmost of these articles have been published in the past 10 weeks. Besides the sheer volume, the peer review process duration has decreased by an even more astonishing rate. A normal review period of 60 days is sometimes shortened to as little as 2 or 3 days. I am sure most authors who had submitted COVID-19 related articles have experienced an "expedited publication process" to allow rapid sharing of information with the goal of providing better patient care and disease containment. Filtering misinformation will become a rather impossible task; even New England Journal of Medicine has retracted an article lately. It will be interesting to see

Citation: Editor. Letter to the Editor: Exponential Increase in COVID-19 Related Publications Compared to Other Pandemic Diseases. Rambam Maimonides Med J 2021;12 (1):eooo9. doi:10.5041/RMMJ.10424.

Copyright: (C) 2020 Antonio Liu. This is an open-access article. All its content, except where otherwise noted, is distributed under the terms of the Creative Commons Attribution License (http://creativecommons.org/licenses/by/3.0), which permits unrestricted use, distribution, and reproduction in any medium, provided the original work is properly cited. [This article was published online first at https://www.rmmj.org.il on October 29, 2020.]

Conflict of interest: No potential conflict of interest relevant to this article was reported.

* E-mail: anthonyseanliu@yahoo.com; liuak@ah.org 
Table 2. A Sample PubMed.gov search.

\begin{tabular}{|lcc|c|c|}
\hline Search Word Used & Hits & $\begin{array}{c}\text { Rough Time } \\
\text { Frame of Articles } \\
\text { Published }\end{array}$ & $\begin{array}{c}\text { Year the Number of } \\
\text { Articles Peaked } \\
\text { (Number of Articles) }\end{array}$ & $\begin{array}{c}\text { Estimated Rate } \\
\text { (Number per Day) }\end{array}$ \\
\hline COVID-19 & 42693 & 2020 & $2020(42679)$ & 181 \\
MERS in 2020 & 20778 & 2020 & $2020(20778)$ & 88 \\
MERS before 2020 & 14048 & Since 2003 & $2003(1389)$ & 0.98 \\
SARS in 2020 & 14744 & 2020 & $2020(14744)$ & 63 \\
SARS before 2020 & 9217 & Since 1994 & $2004(1229)$ & 1 \\
HIV & 367773 & Since 1985 & $2014(17503)$ & 29 \\
H1N1 & 21160 & Since 2000 & $2011(3268)$ & 3 \\
Spanish Flu & 1700 & Since 1980 & $2010(166)$ & 0.12 \\
Ebola & 9449 & Since 2000 & $2015(2070)$ & 1.3 \\
H2N2 & 801 & Since 1972 & $2015(46)$ & 0.05 \\
H3N2 & 8097 & Since 1972 & $2013(547)$ & 0.47 \\
\hline
\end{tabular}

*Not taking into consideration any annual/monthly variation.

if the current literature system as well as almost instantaneous access to articles will guide mankind to a more successful campaign against the current pandemic in comparison to previous ones.

\section{REFERENCES}

1. Pitlik S. COVID-19 Compared to Other Pandemic Diseases. Rambam Maimonides Med J 2020;11(3). doi: 10.5041/RMMJ.10418 